\title{
Fontes Legais nos Livros Didáticos de História
}

\author{
Anne Cacielle Ferreira da Silval
}

Resumo: Apresenta resultados da pesquisa realizada durante o Mestrado em Educação na UFPR, linha de Pesquisa Cultura, Escola e Ensino. A investigação analisou a presença das fontes legais nos livros didáticos de História destinados ao $8^{\circ}$ ano do Ensino Fundamental aprovados pelo Programa Nacional do Livro Didático (PNLD-2011). Observou-se a presença de diversos tipos de documentos históricos, entre eles os documentos legais. Em poucas situações os documentos encontrados foram tratados como fontes e, assim, exploradas de forma a estimular o aluno à contextualização, à problematização e à interpretação. Os resultados da pesquisa evidenciaram avanços em relação à inclusão de diferentes tipos de documento nos livros didáticos, mas evidenciaram também que permanecem presentes as dificuldades em tratar os documentos como fontes, e que, portanto, há ainda a necessidade de aperfeiçoar os livros em relação a esses aspectos.

Palavras-chave: Ensino de História. PNLD. Manuais didáticos. Fontes históricas. Fontes legais.

Abstract: Presents an investigation that searches the presence of legislative sources in the History textbooks destined to the eight grades from basic education approved by the Textbook National Program. The research, of qualitative type, was organized based on the following guiding questions: are the legislative sources used by the authors? If so, do they appear only as illustration or as historical sources? Are there encouragement to investigations

${ }^{1}$ Doutoranda em Educação pela Universidade Federal do Paraná (2014), linha de Pesquisa Cultura, Escola e Ensino. Possui Mestrado em Educação pela Universidade Federal do Paraná (2013), linha de Pesquisa Cultura, Escola e Ensino. Possui licenciatura e bacharelado em História também pela Universidade Federal do Paraná (2009). Já lecionou a disciplina de História para todos os anos finais do Ensino Fundamental e também para todos os anos do Ensino Médio. Seus estudos estão relacionados à área de Educação, com ênfase na Educação Histórica e manuais didáticos. E-mail:annecacielle@bol.com.br 
and problematizations to establish a dialogue with the past? The presence of these historical sources have the objective to build the historical knowledge? Can the presence of these sources positively contribute to the teaching and learning History process? I will use as a methodological procedure the analysis of content, in Franco's (2003) perspective, it was analyzed the History textbooks for eight grade students from basic education. I chose a thematic approach, investigating the presence of legislative sources in the chapters or units related to before, during and after abolition period. The textbooks analysis was made with basis in four categories: cited documents; documents used as illustrations; sources partially explored didactically; and sources with didactic exploration that gives possibilities to construct the historical knowledge. It can be conclude, considering the amount and diversity of sources, that the analyzed textbooks answer to the indications for the use of sources in classroom, this indications are part of the PNLD's evaluation and the speech of experts in teaching of History. It was observed the presence of many kinds of historical sources, among them: engravings, pictures, cartoons, maps, charts, graphics, photographs and memories. The legislative sources were found in a few numbers: 18 in the book $\mathrm{A}$, and 2 in the book B. The analysis of the ways authors included the sources in the analyzed textbooks shows an advantage of source's uses in three situations: only cited, used as illustration, and with a didactic treatment inadequate for the construction of the historical knowledge. In only a few situations these documents were treated as historical sources and, that way, explored stimulating the student to the contextualization, problematization and interpretation, demonstrating the need to improve the textbooks in these ways. The results of the research shows the advances in the inclusion of different kinds documents on the textbooks, but shows also the permanence of difficulties in treating documents as historical sources and, therefore, there is still the need to improve the textbooks in these aspects.

Keywords: Teaching History, PNLD, Textbooks, Historical Sources, Legislative Sources.

\section{Introdução}

Durante o período em que lecionei em escolas da rede Estadual de Ensino, pude perceber que para a maioria dos alunos de ensino básico a História está pronta; a maioria dos alunos não tem clara a ideia 
de que a História se produz, como qualquer outro conhecimento, através da busca intelectual. Foi pensando nisto que elaborei um projeto de pesquisa para o Mestrado em Educação que visasse informar aos alunos que a História é uma ciência particular, que não se limita a considerar a existência de uma só explicação ou narrativa sobre o passado, mas, pelo contrário, que a História possui uma natureza multiperspectivada (SCHMIDT e BARCA, 2009, p. 12).

No ano de 2011, ingressei no Programa de Pós-Graduação em Educação pela Universidade Federal do Paraná com um projeto que propunha, primeiramente, analisar o uso das fontes legais nos anos finais do Ensino Fundamental, pois, no meu entendimento, através do trabalho com fontes históricas em sala de aula, o aluno passa a compreender que a História não está pronta; que a História é uma ciência particular e que não se limita a considerar a existência de uma só explicação ou narrativa sobre o passado.

A pesquisa sobre o uso de fontes justifica-se, pois a historiografia contemporânea provocou uma revolução no conceito de documento histórico e também ampliou as possibilidades de sua utilização pelos historiadores. Do predomínio absoluto da fonte como prova da verdade sobre o passado, os documentos passaram a ser vistos como evidências, os quais precisam ser problematizados e interpretados pelos historiadores e também pelos professores e alunos dentro da disciplina de História. 
O projeto de pesquisa para o Mestrado nasceu, então, com esta preocupação em saber se os documentos, em especial os legais, estão sendo usados e problematizados em sala de aula como sugere a literatura historiográfica. Na pesquisa, entende-se como fontes legais os documentos legislativos, os decretos, as cartas régias, os discursos e pronunciamentos, enfim, todo e qualquer documento que tenha alguma relação com a lei.

Ao longo da trajetória de pesquisa e estudos no Mestrado, o projeto inicial foi aperfeiçoado, e definiu-se que a pesquisa teria como objetivo analisar manuais didáticos destinados aos alunos do Ensino Fundamental, para verificar se e como os autores de manuais didáticos incorporaram o trabalho com fontes legais, considerando-se as recomendações presentes na literatura acadêmica e nos Editais do PNLD.

A escolha pela análise de manuais didáticos deve-se ao fato de que, na cultura escolar, os manuais didáticos sempre ocuparam um lugar de destaque. Os livros ou manuais são elementos tradicionais da cultura escolar ${ }^{2}$ e têm estado presentes na escola ao longo de séculos. Eles podem ser compreendidos como elementos que, inseridos na escola, afetam diferentes dimensões da experiência escolar, em especial a dimensão do ensino e da aprendizagem. Os manuais didáticos e sua presença nas aulas constituem-se em fonte e objeto de pesquisas

2 Sobre o conceito de "cultura escolar" ver FORQUIM, Jean Claude. Escola e Cultura: as bases sociais e epistemológicas do conhecimento escolar. Porto Alegre: Artes Médicas, 1993. 
desenvolvidas por diversos pesquisadores e grupos, incluindo-se o $\mathrm{NPPD}^{3}$.

De acordo com Bittencourt (1998), o manual didático é o principal veiculador de conhecimentos sistematizados e o produto cultural de maior divulgação a que os brasileiros têm acesso na cultura escolar. Ele tem sido um elemento importante para a discussão das questões relacionadas à prática de ensino do conhecimento histórico no âmbito escolar, sobretudo porque é visto como um veículo fundamental de popularização do conhecimento histórico. (BITTENCOURT, 1998).

No caso brasileiro, o século XX foi marcado pela expansão da produção e do uso de manuais escolares, seja para os alunos, seja para professores, como salientam Chaves e Garcia (2011). Ao longo dos últimos cem anos, os livros ganharam força e passaram a influenciar a educação do nosso país, tanto do ponto de vista dos conteúdos de ensino quanto das formas de ensinar, privilegiando concepções e abordagens, indicando estratégias e recursos e, portanto, contribuindo para definir elementos constitutivos do ensino nas diferentes disciplinas escolares. (CHAVES e GARCIA, 2011).

No Brasil, como existem programas nacionais de avaliação e distribuição de livros didáticos a todos os alunos de Ensino

\footnotetext{
${ }^{3}$ Núcleo de Pesquisas em Publicações Didáticas (NPPD) da Universidade Federal do Paraná, que desenvolve ações conjuntas com o Laboratório de Pesquisa em Educação Histórica (LAPEDUH) da mesma universidade, orientadas pela opção de pensar a natureza do trabalho escolar em profunda conexão com a vida social em sua totalidade, o que indica abordagens específicas para examinar todos os elementos que estruturam a vida nas escolas.
} 
Fundamental e Médio, para a maior parte das disciplinas curriculares, em particular o Programa Nacional do Livro Didático (PNLD), o debate sobre os manuais se insere para além da dimensão didática como uma questão política e educativa da maior relevância, como afirma Garcia (2010).

Isto impõe aos pesquisadores o desafio de se aproximar dos sujeitos escolares, em especial professores e alunos, para compreender as formas pelas quais o livro afeta as aulas na dimensão do ensino e da aprendizagem e analisar, portanto, se todo o recurso público aplicado no programa está contribuindo para a melhoria do ensino e da aprendizagem dos alunos. Nesse contexto é que a pesquisa encontra sua justificativa.

A pesquisa investigou a presença das fontes legais nos livros didáticos de História, a partir de algumas questões orientadoras: os documentos legais são usados pelos autores? Se sim, aparecem somente como ilustração ou têm a finalidade de construir o conhecimento histórico? São entendidos como mera ilustração das narrativas históricas apresentadas? São estimuladas indagações e problematizações de forma a estabelecer um diálogo com o passado? A presença dessas fontes pode contribuir positivamente para o processo de ensino e aprendizagem histórica?

O objetivo principal da pesquisa foi, portanto, verificar se as fontes legais têm sido incorporadas aos livros, principalmente em temas relativos ao período pré-abolição, abolição e pós-abolição da 
escravatura no Brasil. Para atender a esse objetivo, defini como material empírico os livros didáticos de História destinados aos alunos do $8^{\circ}$ ano do Ensino Fundamental. Esta escolha se justifica pelos temas propostos para estas séries, ou seja, temas que abordam o período pré-abolição, abolição e pós-abolição da escravatura no Brasil, temas que devem ser apresentados aos alunos das séries finais do Ensino Fundamental, de acordo com as orientações curriculares dos sistemas de ensino.

Metodologicamente, foi utilizada a análise de conteúdo, na perspectiva de Franco (2003). Para essa autora, a partir de uma préanálise dos materiais selecionados, são definidas categorias e hipóteses de trabalho para o desenvolvimento das análises finais.

Neste trabalho, apresento os principais resultados obtidos durante a pesquisa de Mestrado em Educação na UFPR, linha de Pesquisa Cultura, Escola e Ensino.

\section{Pré-Abolição, Abolição e Pós-Abolição nas fontes legais: analisando sua presença nos livros didáticos.}

Sabe-se que hoje é obrigatório o Ensino da Cultura Afrobrasileira e Africana nas aulas de História, por força da Lei 10.639/2003, que alterou a Lei de Diretrizes e Bases da Educação Nacional (Lei 9394/1996) e incluiu no currículo oficial da Rede de Ensino a obrigatoriedade da temática "História e Cultura AfroBrasileira". Os conteúdos devem ser ministrados no âmbito de todo o currículo escolar, em especial nas áreas de História, de Educação 
Artística e de Literatura Brasileira. Deve-se considerar que, em parte, ela respondeu às reivindicações dos movimentos sociais, especialmente do Movimento Negro. Essa lei foi modificada em 2008, tornando obrigatório o estudo da história e cultura afro-brasileira e indígena (LEI $\mathrm{N}^{\mathrm{o}} 11.645$, de 10 de março de 2008).

Com relação à História e Cultura Afro-Brasileira, o Parecer $\mathrm{CNE} / \mathrm{CP}$ n. ${ }^{\circ}$ 3, de 10 de março de 2004, instituiu as "Diretrizes Curriculares Nacionais para a Educação das Relações Étnico-Raciais e para o Ensino de História e Cultura Afro-Brasileira e Africana". O conjunto de leis e as ações políticas organizadas em torno dessa questão também se refletiram nos livros didáticos de História, que passaram a abordar essa temática.

Em torno dessas questões, a partir da década de 1990 a avaliação do PNLD foi exigindo, gradualmente, critérios relativos à cidadania, os quais se fortaleceram na última década como motivos de exclusão de uma obra didática do programa. Essas definições estão relacionadas, portanto, ao conjunto de políticas implementadas pelo Governo Federal coordenadas pelo MEC por meio da Secretaria de Educação Continuada, Alfabetização, Diversidade e Inclusão.

No entanto, a inserção da Cultura e História Africana e AfroBrasileira não se deu de forma imediata e dentro de um mesmo padrão. A revisão de literatura para a dissertação de Mestrado em Educação apontou a existência de pesquisas que constataram ser frequente os 
autores de livros didáticos restringirem suas abordagens às questões da escravidão.

Assim, o recorte temático para o trabalho de análise empírica dos livros didáticos na dissertação foi definido com vistas a localizar fontes legais apresentadas, analisadas ou sugeridas nos capítulos que tratam da pré-abolição, abolição e pós-abolição, temas relacionados com a população africana e afrodescendente no Brasil, não exclusivamente sobre a escravidão.

Para a pesquisa, foram selecionados dois manuais didáticos para analisar a presença ou não das fontes legais, em especial nos períodos que abordam a pré-abolição, abolição e pós-abolição da escravatura no Brasil. A escolha da obra de Joelza Ester Domingues para a análise deveu-se principalmente ao título da obra, "História em Documento - Imagem e Texto" que explicita a posição da autora em relação à valorização dos documentos. Entendeu-se, portanto, que a obra seria um material empírico privilegiado para responder às questões que haviam sido formuladas. Buscou-se, então, verificar como a autora incorporou o trabalho com fontes legais em sua obra didática, considerando-se as recomendações presentes na literatura e nos Editais do PNLD.

A segunda obra escolhida para análise foi a de Alfredo Boulos Júnior. A escolha deste manual didático deveu-se ao fato de que, assim como a de Joelza Ester Domingues, foi aprovada pelo Programa Nacional do Livro Didático (PNLD) em 2011. É destinado aos alunos 
do $8^{\circ}$ ano e é utilizado com frequência pelos alunos de algumas Escolas Estaduais com as quais se estabeleceu contato.

Para análise das obras selecionadas usou-se, metodologicamente, a análise de conteúdo, na perspectiva de Franco (2003). Para examinar os livros foram usadas quatro categorias:

\section{$1^{\text {a }}$ Categoria de análise: documentos citados}

Nesta primeira categoria foram agrupadas fontes citadas pelo autor, mas que não aparecem nos manuais didáticos, ou seja, não estão apresentadas nos livros. Foram analisados os documentos citados ao longo dos capítulos e das unidades selecionadas, documentos estes que aparecem citados ao longo dos textos-base. Os documentos sugeridos complementarmente ao término dos capítulos e das unidades não foram incluídos nesta categoria.

\section{$2^{\mathrm{a}}$ Categoria de análise: documentos usados como ilustração}

A categoria dois refere-se aos documentos históricos que aparecem nos manuais didáticos somente como ilustrações, ou seja, não é sugerida nenhuma atividade de interpretação com os alunos, nem ao menos há indicações dos motivos de sua inserção no manual. 


\section{$3^{\text {a }}$ Categoria de análise: fontes com exploração didática parcial}

Nesta terceira categoria foram incluídas aquelas que, embora sejam tratadas como fontes, as atividades sugeridas, por algum motivo, não levam os alunos à interpretação do documento histórico, como sugerem a literatura e as orientações curriculares nacionais, restringindo as possibilidades de construção do conhecimento histórico.

\section{Categoria de análise: fontes com exploração didática que abre possibilidades de construção do conhecimento histórico}

Esta quarta categoria de análise agrupa os documentos históricos que são tratados pelos autores de maneira adequada, ou seja, são explorados de forma que podem possibilitar aos alunos, com a ajuda de seus professores, construírem um conhecimento histórico.

A partir destas quatro categorias, buscou-se analisar a presença dos documentos históricos, em especial os documentos legais, nos manuais escolhidos.

\section{As fontes legais estão presentes nos livros analisados?}

No livro de Joelza Ester Domingues (livro A), as fontes legais, objeto de interesse desta pesquisa, aparecem nos capítulos analisados num total de 18 , número considerado significativo, e que talvez tenha relação com o fato da maioria delas estarem já disponibilizadas na 
internet e, portanto, serem de fácil localização. Quanto à forma como foram trabalhadas, a autora opta por fazer questionamentos e, através de perguntas dirigidas, busca levar os alunos à interpretação dos documentos.

$\mathrm{Na}$ análise realizada, pode-se perceber que o livro A atende às indicações para a utilização de fontes em sala de aula, indicações estas que fazem parte dos critérios de avaliação do PNLD e do discurso de especialistas da Didática da História, incluindo-se a abordagem da Educação Histórica, na perspectiva do filósofo da História Jörn Rüsen. No material empírico analisado observou-se a presença de diversos tipos de fontes históricas, entre elas: gravuras, quadros, charges, mapas, tabelas, gráficos, fotografias, memórias e as fontes legais. Portanto, do ponto de vista da quantidade e diversidade, pode-se concluir que o livro A pode ser considerado adequado, como se verifica no quadro a seguir: 


\begin{tabular}{|c|c|c|}
\hline Tipo & Quantidade & $\begin{array}{l}\text { Número das páginas que contêm os } \\
\text { documentos históricos }\end{array}$ \\
\hline Mapa & 5 & Páginas: 73, 128, 243, 259, 267 \\
\hline Desenho & 10 & $\begin{array}{c}\text { Páginas: } \begin{array}{c}121,133,151,165,239,241,254, \\
255,265\end{array}\end{array}$ \\
\hline Pintura/gravura & 33 & $\begin{array}{c}\text { Páginas: } 76,123,125,127,129,130,131, \\
135,137,139,141,143,144,145,146,153, \\
159,162,243,271,274,276\end{array}$ \\
\hline Fotografia & 41 & $\begin{array}{l}\text { Páginas: } 73,75,78,146,147,148,155,157, \\
236,245,247,249,251,259,261,267,269, \\
\text { 272, 273, 274, } 279\end{array}$ \\
\hline Texto como fonte & 11 & $\begin{array}{c}\text { Páginas: } 75,76,77,125,137,143,247,249 \text {, } \\
267,271\end{array}$ \\
\hline Cartaz/anúncio & 11 & Páginas: $247,257,259,261$ \\
\hline Gráfico & 5 & Páginas: 171, 249 \\
\hline Charge/caricatura & 8 & Páginas: 167, 169, 262, 263, 266 \\
\hline Tabela & 9 & Páginas: 73, 128, 153, 171, 243, 247, 257 \\
\hline Letra de música & 1 & Página: 155 \\
\hline Jornal & 3 & Páginas: $157,160,161$ \\
\hline Fonte Legal & 18 & $\begin{array}{l}\text { Páginas: } 75,123,127,137,139,141,143, \\
155,157,167,245,269\end{array}$ \\
\hline
\end{tabular}

QUADRO 1- DOCUMENTOS HISTÓRICOS PRESENTES NO LIVRO A (LIVRO DO ALUNO)

FONTE: Pesquisa da autora (2012).

$\mathrm{Na}$ análise qualitativa, com base nas quatro categorias definidas, o que se pode verificar é que muitas das fontes legais são apenas citadas. Pode-se observar também que a maioria das fontes imagéticas foram utilizadas com uma finalidade ilustrativa, o que também se aplica aos demais tipos de fontes localizadas. Uma parte significativa delas, no caso do Livro A, são tratadas didaticamente, evidenciando o entendimento da autora quanto ao fato de que é necessário trabalhar com as fontes. Contudo, também para todos os tipos de fontes, em raras situações se pode observar um tratamento 
didático adequado que abrisse possibilidades de construção do conhecimento histórico.

A análise das orientações presentes no livro A do docente revela a valorização e a recomendação do trabalho com as fontes em sala de aula; no entanto, não há indicações quanto a alguns elementos que seriam imprescindíveis nesse trabalho, como, por exemplo: informar os alunos sobre a natureza do documento - se é um documento oficial, se é um documento que exprime uma opinião, ideia e gosto, ou se é um documento religioso. Também não foi encontrada, nas orientações dadas para o professor pela autora do livro A, a recomendação para informar aos alunos qual é a origem do documento (onde e quando o documento foi encontrado), a data de sua produção e o autor do documento (autor conhecido ou não, individual ou coletivo). Pode-se supor que os professores sabem e conhecem essas necessidades, mas tratando-se de um manual de orientação, que cumpre determinadas exigências do PNLD, talvez essas contribuições fossem interessantes.

No livro B, livro de Alfredo Boulos Júnior, encontrou-se somente duas fontes legais nos capítulos e unidades relacionadas ao tema pré-abolição, abolição e pós-abolição da escravatura no Brasil. O autor privilegia as imagens como documentos históricos ao longo de todo o seu livro, e isto fica claro nas orientações destinadas aos professores sobre como trabalhar com o manual didático do aluno nas aulas de História. O autor dedica uma atenção especial para explicar 
como se deve "trabalhar com as imagens" em sala de aula, tema que constitui uma seção específica do manual, em detrimento dos outros documentos históricos.

Do ponto de vista quantitativo, pode-se concluir, com base na análise realizada no manual dos alunos e nas orientações presentes no livro do docente, que o livro de Boulos Júnior atende as indicações para a inclusão de documentos no ensino, como se pode verificar no quadro a seguir: 


\begin{tabular}{|c|c|c|}
\hline Tipo & Quantidade & $\begin{array}{c}\text { Número das páginas que contêm os } \\
\text { documentos históricos }\end{array}$ \\
\hline Mapa & 11 & $\begin{array}{c}\text { Páginas: } 8,9,12,20,24,53,59,204, \\
217,241,243\end{array}$ \\
\hline Desenho & 3 & Páginas: $15,21,228$ \\
\hline Pintura/gravura & 61 & $\begin{array}{l}\text { Páginas: } 13,16,17,18,27,52,54,57, \\
\text { 61, 62, 63, 183, 184, 185, 188, 189, } \\
\text { 190, 191, 194, 195, 196, 198, 199, 200, } \\
\text { 201, 203, 205, 206, 207, 209, 210, 213, } \\
214,220,221,235,237,245,246,247, \\
249,258,262,263,265,267,275\end{array}$ \\
\hline Fotografia & 70 & $\begin{array}{l}\text { Páginas: } 10,11,14,18,19,23,25,28, \\
51,55,56,60,64,67,69,180,181, \\
182,183,186,187,213,218,219,220, \\
222,224,225,230,235,240,242,244, \\
249,251,252,253,254,259,260,262, \\
264,266,268,271,272,275\end{array}$ \\
\hline $\begin{array}{l}\text { Texto como } \\
\text { fonte }\end{array}$ & 18 & $\begin{array}{c}26,28,67,189,192,193,195,21,226, \\
227,229,254,257,273,274\end{array}$ \\
\hline Cena de filme & 1 & Página: 68 \\
\hline Gráfico & 3 & Páginas: 58, 60, 218 \\
\hline $\begin{array}{c}\text { Charge/caricatu } \\
\text { ra }\end{array}$ & 10 & $\begin{array}{c}\text { Páginas: } 215,234,236,238,239,255 \text {, } \\
261,262,270,277\end{array}$ \\
\hline Capa de livro & 1 & Página: 257 \\
\hline Tabela & 3 & Páginas: 240, 248, 250 \\
\hline $\begin{array}{l}\text { Capa de } \\
\text { partitura }\end{array}$ & 1 & Página: 276 \\
\hline $\begin{array}{l}\text { Anúncio de } \\
\text { Jornal }\end{array}$ & 1 & Página: 275 \\
\hline Fonte Legal & 2 & Páginas: 24, 237 \\
\hline
\end{tabular}

QUADRO 2 - DOCUMENTOS HISTÓRICOS PRESENTES NO LIVRO B

FONTE: Pesquisa da autora (2012) 
Fica evidenciada também a predominância absoluta de documentos visuais, como chamados nos documentos do PNLD (Editais e Guias). As fontes legais que foram o objeto de maior interesse nesta pesquisa aparecem pouco e são, sobretudo, citadas, não estando presentes no manual didático como documentos históricos. Da mesma forma que no manual do professor do Livro A, há orientações para trabalhar com as fontes imagéticas em sala de aula; no entanto, não há orientações específicas que indiquem os elementos constitutivos do trabalho com fontes, quando o objetivo é fazer o aluno construir o conhecimento histórico.

Do ponto de vista da forma pela qual os documentos aparecem no Livro B, uma grande parte das situações está localizada nas categorias 1 e 2, evidenciando que as fontes ou são apenas citadas, ou são usadas com finalidade ilustrativa. Mesmo no trabalho com imagens, observa-se um tratamento didático inadequado para as indicações existentes na literatura acadêmica e nos documentos oficiais de orientação curricular.

\section{Considerações finais}

Ao finalizar este trabalho, deve-se apontar que as pressões do campo acadêmico e das orientações curriculares para que as fontes estejam presentes nas aulas de História parecem ter resultado em uma incorporação quantitativamente significativa de documentos nos livros 
analisados. Além da diversidade, deve-se destacar dos quadros apresentados a predominância das fontes imagéticas, justamente as que têm merecido atenção mais acentuada nos debates sobre o Ensino da História.

Por outro lado, mesmo com a ampliação dos debates sobre as Linguagens e sobre os diferentes tipos de fontes, verifica-se que nos livros analisados as letras de música foram pouco incluídas. Documentos escritos, de forma geral, também não foram encontrados em número significativo, talvez por efeito do movimento de valorização das imagens.

Considerada a ampliação do acesso a fontes legais que vem se verificando pela digitalização de documentos e sua disponibilização em sites, entende-se que seria relevante retomar a discussão sobre os documentos escritos e em especial os legais, discutindo suas contribuições nas aulas de História e procedimentos de caráter metodológico que são adequados ao ensino.

\section{Referências}

BITTENCOURT, Circe. Livros didáticos entre textos e imagens. In: O saber histórico na sala de aula/ Circe Bittencourt (Org.). São Paulo: Contexto: 1998, p. 69-90.

BOULOS Júnior, Alfredo. História e cidadania, $8^{\mathbf{0}}$ ano/ Alfredo Boulos Júnior. - São Paulo: FTD, 2009. ( Coleção História: sociedade \& cidadania). 
CHAVES, Edilson Aparecido; GARCIA, Tânia Maria F. Braga. Critérios de escolha dos livros didáticos de História: o ponto de vista dos jovens. In: X Congresso Nacional de Educação (EDUCERE) $-1^{\circ}$ Seminário Internacional de Representações Sociais, Subjetividade e Educação - SIRSSE. Pontifícia Universidade Católica do Paraná, Curitiba/PR, 2011, p. 1-12.

DOMINGUES, Joelza Ester. História em Documento - Imagem e Texto, $\mathbf{8}^{\mathbf{a}}$ ano/ Ed. Renovada. São Paulo: FTD, 2009. (Coleção história em documento: imagem e texto).

FORQUIM, Jean Claude. Escola e Cultura: as bases sociais e epistemológicas do conhecimento escolar. Porto Alegre: Artes Médicas, 1993.

FRANCO, Maria Laura P. B. Análise de conteúdo. Série Pesquisa, v. 6, Brasília: Liber Livro, 2003.

SCHMIDT, Maria Auxiliadora; BARCA, Isabel (Org.). Aprender história: perspectivas da educação histórica. Ijuí: Ed. Unijuí, 2009. (Coleção cultura, escola e ensino)

Artigo recebido em 04/07/2014, aceito em 02/08/2015 